\title{
Caveolae and Caveolins: Multiple functions and Architectural Adaptation in various Head and Neck Diseases
}

\author{
Bina Kashyap* and P Sridhar Reddy \\ Department of Oral Pathology, Buraydah Private Dental College, Buraydah, Saudi Arabia
}

Received: May 15, 2016; Accepted: June 31, 2016; Published: July 05, 2016

*Corresponding author: Bina Kashyap, Department of Oral Pathology, Buraydah Private Dental College, Buraydah, Saudi Arabia; Tel no: +966 504663028; E-mail: binakashyap@yahoo.co.in

\begin{abstract}
The cell consists of numerous small invaginations of the plasma membrane, among which caveolae describes its novel role in transport, in communication between intra- and extracellular environment and transport of macromolecules across endothelial cell layer. Caveolin 1 is a major component of the caveolae, allowing purification of caveolar membranes and establishment of a list of caveolar proteins. Numbers of signaling components are present in caveolae which serve as organizing platform of signaling components. Caveolae are remarkably stable structures but their functional significance in cells and organisms remains poorly understood. Hence, this article emphasize the importance of mysterious, hidden, two fold and secrete functions brought about in the caveolae and by caveolae proteins at the plasma membrane in different diseases affecting head and neck region.
\end{abstract}

Keywords: Cell; Caveolae; Extracellular; Invaginations; Intracellular; Plasma membrane

\section{Introduction}

Cancer is a heterogeneous, multifactorial, multifaceted and multistep process. It is a complex process involving the contribution of many different factors. The suggested categories of cancer causation include spontaneous, hereditary, environmental and interaction of gene and environment. Head and Neck Cancer has become one of the chief causes of death worldwide and mortality has doubled in the last 20 years. It is the sixth most common human malignancy and global incidence is rising at an alarming rate due to environmental changes. The spread of cancer from its primary site and its subsequent growth in secondary sites is the most fatal aspect of the disease [1]. Many genes and proteins, which are known to play essential roles during embryonic development, are altered or abnormally expressed in cancerous cells.

Caveolae (plasmalemmal vesicles) were first identified in 1953-1955 as endocytic structures that transport molecules across endothelial cells [2]. In Latin "Caveolae" means "little caves", which are small plasma membrane lipid rafts of 50 - 100 nanometer in size and was discovered by electron microscopy in 1953. Under transmission electron microscopy, it appeared as flask-shaped plasma membrane invaginations of strikingly regular shape and size $(\approx 70 \mathrm{~nm}$ average outer diameter $)$ that lack a membrane dense coat. The caveolae are present in most of the cells but are predominant in terminally differentiated mesenchymal cells including endothelial cells, vascular smooth muscle cells, adipocytes, fibroblasts, type I pneumocytes of the lung and striated muscle cells $[3,4,5]$.

Caveolin (Cav) and Cavin are the key protein components of caveolae which are supplemented in glycosphingolipids and cholesterol. Caveolins are proteins closely associated with caveolae and are also known as Cav - 1 or VIP21 (Vesicular Integral-membrane Protein of $21 \mathrm{kDa}$ ). VIP21 was cloned as component of the vesicular transport machinery localized at the plasma membrane, Golgi bodies and on vesicular structures [6,7]. Cav -1 was the first member of caveolin family to be identified as a tyrosine-phosphorylated protein in cells transformed by the Rous sarcoma virus. In mammals, three caveolin genes are expressed (caveolin 1, caveolin 2, caveolin 3) and it codes for 4 protein isoforms (caveolin- $1 \alpha$, caveolin- $1 \beta$, caveolin 2 and caveolin 3). Most of the body tissues express at least one of these isoforms. Caveolin - 1 high level expression was observed in adipocytes, fibroblasts, endothelial cells, smooth muscle cells and type 1 pneumocytes. Caveolin - 2 expressions was observed with caveolin -1 for membrane localization and stability whereas caveolin - 3 was predominantly expressed in heart and skeletal muscle cells. So, among these three caveolins, only Cav 1 and Cav 3 are required for the caveolae biogenesis. Monier, et al. showed high affinity of Cav 1 for cholesterol which helps it to form oligomer and this Cav 1 oligomerization is a key feature for the formation of complete caveolae structure [8].

Cavins are other heteromeric protein complexes that are recruited to the caveolae. Four Cavins are identified so far in mammals these includes Cavin 1/PTRF(Polymerase I and Transcript Release Factor), Cavin 2/SPDR (Serum Deprivation Response Protein), Cavin 3/SRBC (Sdr-Related Gene Product That Binds To C-Kinase) \& Cavin 4/MURC (Muscle - Restricted Coiled - Coil Protein) [9].

\section{Structure \& Formation of Caveolae}

Caveolae are the non-coated pits showing close resemblance to the clathrin - coated pits which are present in all the cells 
and have many receptors responsible for receptor - mediated endocytosis whereas caveolae plays quantitatively minor role in endocytosis. These are secured at the plasma membrane via cytoskeleton of the cell. Actin and actin connectors such as filamin A, Eps-15 Homology Domain - containing protein 2 (EHD2) helps attachment of caveolae at the membrane site. Cavin proteins are believed to be the important organizational element of the caveolae. Liu L, et al. \& Hill MM, et al. (2008) showed that cavins are recruited to the membrane site by the caveolins and these both are required for caveolae formation [10,11]. Ludwig G, et al. and Gambin Y, et al. in their ultrastructural study by electron microscopy and X-ray crystallography proposed that cavins along with Cav 1 plays an crucial role in caveolae assembly. Also showed that the association of cavin 1 to its counterpart cavin 2 $\& 3$, is in the ratio of 2 to $3: 1$, whereas its association with Cav 1 showed the ratio of $1: 4[12,13]$.

Hansen CG, et al. identified two new caveolar proteins namely EDH2 protein and Pacsin2/syndapin-11. EDH2, an ATPase, does not form caveolae but helps in its stabilization at the membrane site and is present in the neck of caveolae. Any defect either increase or decrease of EDH2 will directly affect the endocytosis function brought about by caveolae. Pacsin 2 plays its role in morphogenesis by localizing itself partially with caveolae through a membrane curvature binding domain (BAR). Alterations in pascin 2 results in altered morphology of caveolae thereby causing decrease in Cav 1 and cavin proteins $[14,15,16]$.

Cytoskeletons of the cell like actin filaments, intermediate filaments and microtubules, are all associated with caveolae. Caveolaes involves them in intracellular signaling by uniting signaling boards at the cell membrane. It has been showed that these caveolaes have been involved in several signaling pathways such as MAPK (Mitogen Activated Protein Kinase), AKT/PKB (Protein kinase B), Src Kinases (sarcoma family kinases), Rho and Rac 1 GTPase.

\section{Caveolin and Caveolin hypothesis}

Caveolins isoform, the Cav1 and Cav2 genes are in close proximity on human chromosome 7q31.1, while Cav3 is located on the 3 p25 chromosome and are predominantly expressed in plasma membrane, but can also be found in the Golgi, the endoplasmic reticulum, at cytosolic locations, and in vesicles $[17,18]$. Lisanti $b$, et al. suggested that all the three isoforms have both an $\mathrm{N}$ and $\mathrm{C}$-terminus in the cytoplasm and a long membrane spanning hairpin-like domain. Also, Cav proteins exist as monomers in the Golgi apparatus but undergo homooligomerization upon being transported to the plasma membrane [19]. Cav 1 has high affinity for cholesterol and its oligomerization is key step for the formation of caveolae structure.

Studies on caveolins function have opened a door for some of the proposed hypothesis like caveolin scaffolding domain hypothesis and caveolae signaling hypothesis. These hypotheses were in support to understand the apparent diverse function of Cav 1 \& Cav 1 interacting molecules. Recently, Lamaze C and Torrino S proposed new hypothesis "mechano-dependent caveolae disassembly/reassembly" [20].

\section{Caveolin Scaffolding Domain Hypothesis}

Oligomerization function of caveolin results in scaffolding of the membrane due to its interaction with several signaling molecules. It has been outlined that Cav 1 Binding Motif (CBM) is present in several signaling proteins which allows the interaction in the précised region with Cav Scaffolding Domain (CSD) near the plasma membrane. Although these interactions often suppresses the signaling activity or stimulates the scaffolding domain activity or has no effect at all. So it is suggested that the scaffolding domain might only be a sticky region that binds nonspecifically to many proteins present within the cell. Fernandez et al. [21,22] \& Schlegel A et al in their study on the structure of caveolin showed that amino acids 79 - 96 of the scaffolding domain have $\alpha$ - helix secondary structure and the principal interacting surface of the scaffolding domain is a simple helix which mediates lateral interactions between caveolins and a tendency to interact non specifically with membranes.

Cav 1 modulates signal transduction at the scaffolding region through an interaction with lipids mainly cholesterol. Experimental studies and genetic evidences have shown Cav 1 importance in maintaining caveolae cholesterol levels. It functions to maintain the caveolae lipid scaffold by replacing oxidized cholesterol with the new cholesterol. Hence, in caveolae scaffolding domain hypothesis caveolae lipid itself form a scaffold that systematizes multiple signaling molecules and controls their interactions.

\section{Caveolin Signaling Hypothesis}

This hypothesis highlights the role of caveolins mainly caveolin 1 as a negative regulators of diverse signaling molecules. It has been shown that the lipid raft caveolae has highly ordered caveolin proteins micro domains located within the plasma membrane. Their presence in Golgi, endoplasmic reticulum, vesicles and cytosol, extends their potential reach in regulating signals. They can function as scaffold as well as membranous signaling molecules. Specific motifs within the caveolin proteins aid to recruit lipids and proteins to caveolae thus enabling intracellular transferring of cellular apparatus and regulation of signaling pathway $[23,24,25]$. On the other hand, Machleidt T, et al. [26] in 2000 suggested that there is lack of genetic evidence to assess whether scaffolding domain function as a repressor or activator of cell signaling. Mutating the interacting region of scaffolding domain showed impaired trafficking of Golgi apparatus but the signal transduction through the scaffolding did not show any change. Hence, confirming that Cav 1 may not play strict role in suppressing the signal transduction at cell membrane scaffolding domain site.

\section{Mechano-Dependent Caveolae Disassembly/ Reassembly}

This hypothesis suggests that caveolae play an important role in adaptation of cells to mechanical stress. Cells tolerate many forces during its activity such as compressive, tensile, shear and 
hydrostatic, and all these are involved in shaping, developing and maintaining the tissue structure. It was suggested that in the tumor, the physical forces within the complex microenvironment change with a myriad level of effect on the cells and tissues $[27,28]$. Paszek MJ, et al. examined tissue rigidity, tumor behavior and matrix stiffness and suggested that these are directly related to tumorigenesis. Lopez JI, et al. suggested that the Cav 1 presents dual role in tumorigenesis, first, as loss of expression during transformation and second, as a re-expression in the advances stages of tumor growth. Sinha B, et al. in 2011, presented with a threefold increase in free Cav 1 at the plasma membrane under hypo - osmotic shock condition which lead to mechanical disassemble of the caveolar structure. Once the mechanical force was removed the caveolae reassembled, maybe due to reduction of the amount of free cav 1 at the plasma membrane. Hence, the On/Off cycle of caveolae disassembly/reassembly due to mechanical force may cause an impact on either activation or inactivation of the signaling molecules. So, at early stages of tumorogenesis, the mechanical forces encountered by the tumor cells and the supporting stromal cells would be minimal to which the caveolae responds by flattening out and releasing free cav 1 at the plasma membrane, which in turn will activate anti tumoral effect by inhibiting the pro tumoral signaling activity. But in the later stages of tumorigenesis, the mechanical force and tension would increase to an extend that caveolae would activate pro tumoral signaling and suppress anti tumoral signaling effects $[20,29,30,31]$.

\section{Functions of Caveolin}

The most appreciated function of caveolae in wide variety of cellular events includes endocytosis, transcytosis of proteins, cholesterol haemostasis, cell migration, cell polarity, calcium signaling and other signaling events. Recent evidences indicated that caveolins 1 confers long lasting stability and is an unusual protein that can be an integral membrane protein or a soluble membrane protein in multiple cellular compartments. In addition, it can interact with both lipids and lipid anchored on several proteins and these interactions make its prime function in lipid transport, membrane traffic and signal transduction [32].

Smart E, et al. in 1996 [33] strongly suggested that caveolin 1 plays a role in import and export of cellular cholesterol. He observed that in normal human fibroblasts cholesterol moves directly to the plasma membrane after being synthesized in the endoplasmic reticulum and then to the extracellular space. Plasma membrane cholesterol can also move directly to the endoplasmic reticulum. Graf GA in 1999, [34] showed binding of SR-B1 (Scavanger receptor class B membrane 1) to free cholesterol, cholesterol esters and cholesterol ethers in High Density Lipoproteins (HDL) which allows their movement to the intracellular sites from caveolae. Caveolin 1 is also present in the cytosol of many cells, where it gets associated with the cholesterol and behaves like a protein that is embedded in a particle with the size and light density of HDL. Ito J, et al. [35] showed that apoA-1(apolipoprotein A 1) binding to SR-B1 which stimulates the formation of cytosolic lipid particle containing caveolin 1 , cholesterol and phospholipid. Hence, both intracellular and extracellular lipid transport function is carried out by caveolin 1 Figure $1 \& 2$.

Membrane trafficking takes place at the caveola where caveolin 1 attracts proteins and functions as molecular engine that powers membrane invagination and budding. The exact way by which caveolin 1 performs this function is not known but the little evidence suggests its interaction with several tyrosine kinases and EGFR (Epidermal Growth Factor Receptor). Li PU, et al. [36] challenged the role of caveolin 1 in caveolae internalization and suggested that the Autocrine Motility Factor (AMF) is transported through caveolae pathway directly to the Endoplasmic Reticulum (ER) without the involvement of caveolin 1 and this delivery of AMF to ER is 5 times faster than the

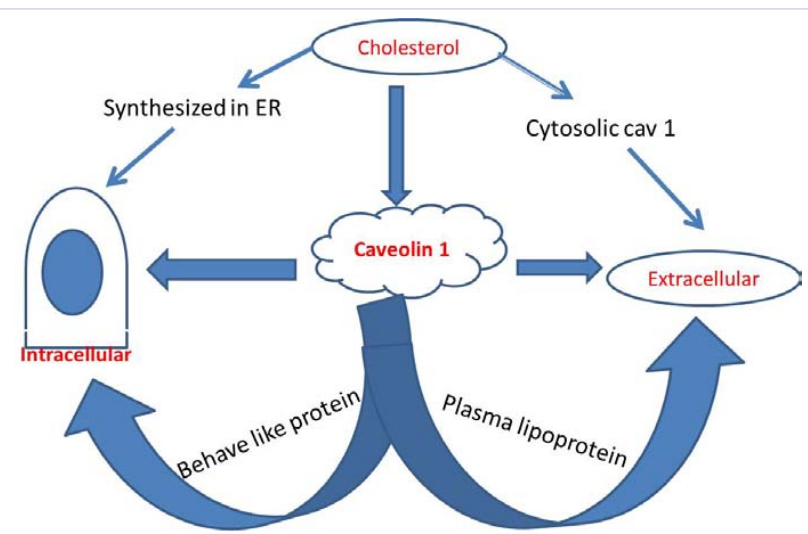

LIPID / CHOLESTEROL TRAFFIC

Figure 1: Role of Caveolae in lipid/cholesterol traffic.

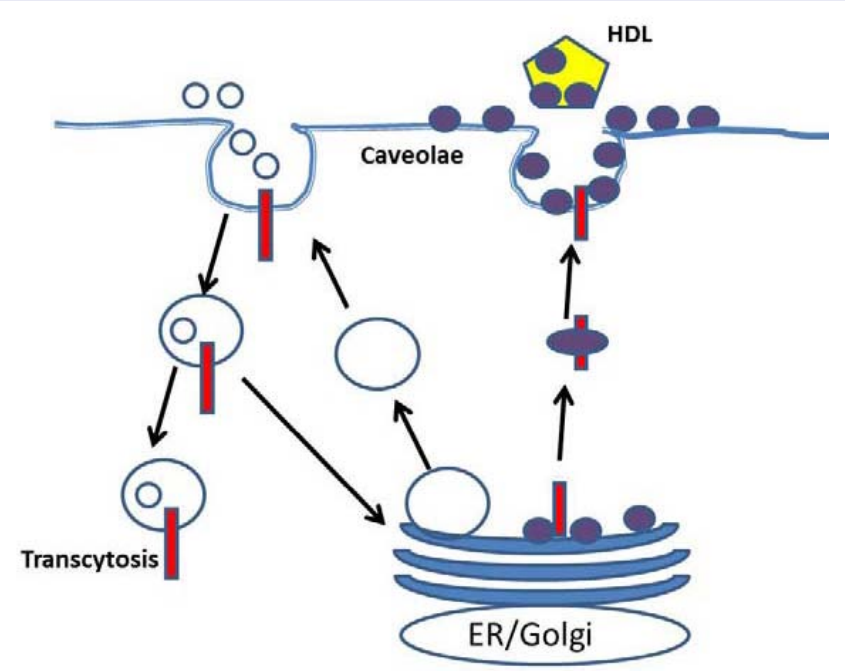

FUNCTION OF CAVEOAE

Figure 2: Transcytosis and High Density Lipoprotein import and export through caveolae. 
cells expressing caveolin 1 . The delivery of AMF to ER appears to occur in cells deficient in caveolin 1. In the experimental study on caveolin 1 deficient cells, numerous flask shaped membranes that were morphologically similar to caveolin 1 expressing cells were observed which contained AMF receptors. This suggests that internalization of protein through the caveolae pathway is the same regardless of whether the cells express caveolin 1. Internalization of caveolae is tightly regulated by PKC (Protein Kinase C) and tyrosine kinase. The unknown pathogens control this regulatory system and enhance their own internalization through caveolae by activating an unknown tyrosine kinase. Hence, caveolin 1 indirectly regulate the interaction of caveolae with the actin rich region and /or with actin binding proteins thereby controlling caveolae at the cell surface or in the interior of cell. The overall interaction at the membrane site is controlled by the caveolin 1 Figure 3.

\section{Do Cav 1 behave like a tumor suppressor!!}

Cav 1 gene is located at D7S522 locus of human chromosome $7 q 31.1$ and is suggested to be erased in various human cancers such as head and neck cancers, breast, kidney, ovary, prostate and colon, thereby highlighting it to be a tumor suppressor [37, 38]. Lee H, et al. [39] and Rieth MD [40] in their experimental studies supported the hypothesis of Cav 1 as tumor suppressor by describing sporadic negative mutant of Cav 1 P132L. They showed that expression of P132L mutant resulted in the absence of caveolae at the plasma membrane but the mutant itself resided in the golgi apparatus. If the mutation of both the mutant and wild type Cav 1 is expressed in the cells and localized to the golgi apparatus then this results in mispleating of the proteins. The mutant causes up regulation of several signaling molecules like EGF, HGF etc and cellular revolution. Bonuccelli G, et al. [41] demonstrated that Cav 1 P132L acts as a loss of function mutation thereby promoting the recurrences in breast cancer. Hayashi, et al. reported $16 \%$ mutation in a sample of 92 breast cancer patients whereas Li T, et al. [42] observed mutation in only $9 \%$. Most of the tumors presented Cav 1 activity combined with oncogenes and signaling molecules which either results

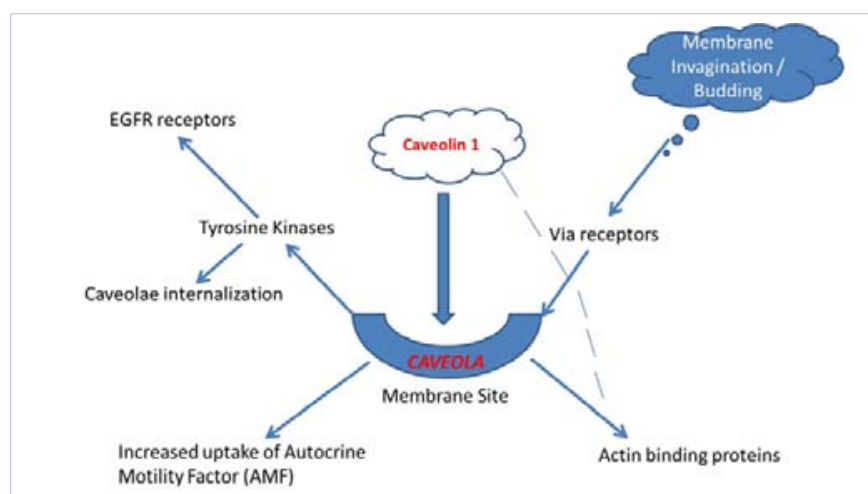

MEMBRANE TRAFFIC / CAVEOLAE INTERNALIZATION

Figure 3: Role of caveolae at the membrane site. in down regulation of Cav 1, over expression of cyclinD1, ERK hyper activation and/or hyper proliferative activity. Glenney JR [43] suggested that Cav 1 may be a target for inactivation during oncogenesis; hence in most of the cancers the Cav 1 is down regulated. However, elevated expression of Cav 1 has been associated with the metastasis and negatively correlated with patient survival $[44,45]$. Hence, Cav 1 is considered as "conditional" tumor suppressor.

\section{Do Cav 1 is an oncogene!!}

Despite number of evidences that support Cav 1 as a tumor suppressor, there are evidences that suggest a drastically different role of Cav 1. Cav 1 expression may vary (reduced, unchanged or over expressed) depending on the tissue involved. Li L, et al. and Tahir, et al. [46,47] stated that in early stages of tumorigenesis, Cav 1 inhibits cell cycle progression and cell proliferation whereas in advance stages it progresses cancer and metastasis.

A variety of mechanisms have been recommended to elucidate how caveolin-1 may stimulate tumorigenesis. In prostate cancer cells, increased caveolin-1 levels were found to favor growth factor release and regulation by a positive feedback loop that enhances tumor cell invasiveness [48] and VEGF-associated angiogenic signaling [49]. In breast cancer cells, caveolin-1 was shown to associate with type 1 matrix metalloproteinase, thereby promoting invadopodia formation and matrix degradation, and this provides a mechanism for increased invasiveness [50]. Successful tumor cell migration requires proper cell polarization, directionality, and the ability to invade new surrounding matrices and cav 1 is one among them, proved in different experimental research studies [51,52].

Cav 1 which is highly expressed in endothelial cells is down regulated during the proliferative phase and up regulated during the differentiation phase of angiogenesis. In transmigrating endothelial cells, caveolin-1 was shown to interact with intermediate filaments [53]. In provision to this, an evidence involves caveolin-1 in regulating the small GTPases Rho and Rac, which are required for actin dynamics, cell polarization, and directional migration $[54,55,56]$. The role of caveolin- 1 in tumorigenesis is not limited only on mechanisms of migration and invasiveness. But it was associated with various expression linked to the attainment of qualities associated with malignant cell behavior, including Multidrug Resistance (MDR) and metastasis, as well as poor prognosis.

The caveolin-1 plays a dual role in cancer. The uncertainty of caveolin-1 function is best resolved by the model for colon cancer. Early on the cellular environment, caveolin-1 is reexpressed, it develops traits consistent with a role as a tumor suppressor. Regulation of the Wnt signaling pathway is depicted as one of the possibility. Caveolin-1 into tumor cells that still express E-cadherin leads to the repression of beta - cateninTcf/Lef-dependent transcription of genes, such as cyclin D1, cox-2, survivin and c-myc. However, during tumor progression multiple changes occur at the molecular level (i.e., genome 
instability, genetic mutations and/or epigenetic alterations). One such possibility is the loss of E-cadherin. In this situation of cellular environment, caveolin-1 can no longer repress pathways associated with its role as a tumor suppressor. Instead, traits of the molecule prevail that favor the development of Multi-Drug Resistance (MDR) and metastasis. Therefore, it was suggested that caveolin-1 is a "conditional" tumor suppressor and that its ability to promote or suppress tumor development depend both on the cellular context and environmental conditions [57] Figure 4.

\section{Role of Cav 1 in tumor microenvironment!!}

The approaches that cancer cells procure to achieve the invasive properties require genetic and molecular alterations that are highly complex. Cancer growth is never a symmetrical growth instead it is an asymmetrical growth involving the growth of not only the tumor cells but also the supporting cells such as inflammatory cells, immune cells and the stromal fibroblasts. Cav 1 is shown to be expressed in the stromal fibroblasts (which tend to be myofibroblasts showing increased expression of a smooth muscle actin) $[58,59,60,61]$ the loss of which could promote tumor growth by up regulating the (Extracellular Matrix) ECM components. In vitro studies showed that Cancer Associated Fibroblasts (CAFs) consistently expressed Cav 1 to guide the migration and invasiveness of the cancer cells. In vivo studies reported that Cav 1 remodels the peritumoral and intratumoral microenvironment so as to facilitate tumor invasion and the metastatic potency [62].

Various treatments can enhance the ability of fibroblasts to stimulate tumor cell invasion which include irradiation ${ }^{[63]}$ and reactive oxygen species $[64,65,66]$ as well as lifestyle-correlated factors, such as cigarette, smoke [67] and areca nut extract [68]. Fibroblasts have also been shown to encourage tumor cell invasion through secretion of a number of factors, including chemokine (C- $\mathrm{C}$ motif) ligand 2, stromal cell-derived factor-1, TGFb, IL-33, MMP2, EGFR ligands, and Hepatocyte Growth Factor (HGF).

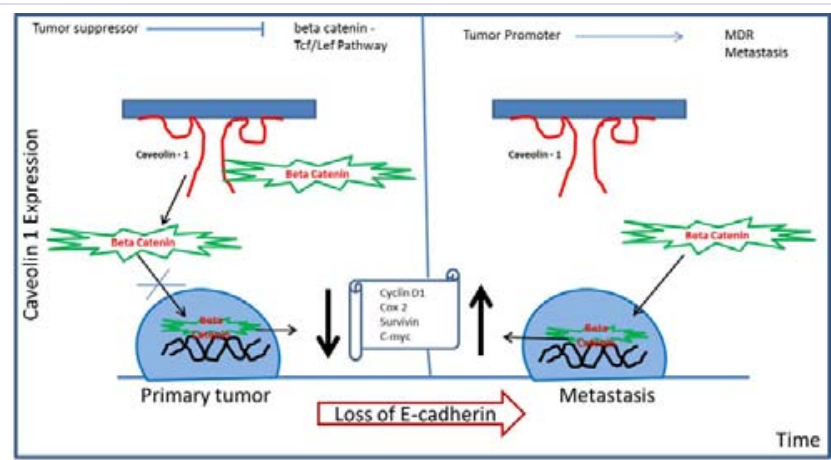

Dual Role of Caveolin - 1 in tumor growth

Figure 4: Dual role of caveolin 1 in tumor growth.

\section{Role of Cav 1 in angiogenesis!!}

Angiogenesis is another major factor in the process of tumor growth, motility and invasion. Cav 1 is shown to control several aspects of endothelial cell functions in normal as well as pathological condition. Endothelial cells can secrete (epidermal growth factor) EGF to induce EMT and invasion [69].Under hypoxic condition, tumor cells will secrete angiogenic factors such as Vascular Endothelial Growth Factor (VEGF) and basic Fibroblast Growth Factor (bFGF) which induces neovascularization. Tumorassociated endothelial cells has shown experimentally to stimulate invasion in vitro through the secretion of IL-8 (Interleukin - 8) [70] and CXCL1 [Chemokine (C-X-C motif) ligand 1] [71]. Hypoxia in the tumor microenvironment can induce Notch and EMT factors, such as Slug and Snail, to increase invasion [72,73]. In addition, MMP-9 can be induced by hypoxia to enhance invasion in a $\mathrm{Na}+\mathrm{H}+$ exchanger $1-$ dependent fashion [74]. Various other studies showed that Cav 1co- localizes with VEGF in tumor associated endothelial cells and promotes angiogenesis whereas the depletion of Cav 1 in endothelial cells affect cell migration and reduced angiogenesis $[75,76]$.

Tkachenko E, et al. showed that in prostate cancer Cav 1 stimulate specific angiogenic activities through the modulation of P13K-eNOS (Phosphatidylinositol 3-Kinase-endothelium nitric oxide synthase) pathway [77]. NO (Nitric Oxide) was discovered by Furchgott and Zawadzki as "Endothelium-Derived Relaxing Factor" (EDRF). It soon became obvious that EDRF, like nitroglycerine, activates soluble guanylate cyclase in vascular smooth muscle by binding to its active haeme centre. The three NOS isoenzymes (neuronal, endothelial and inducible) and among all eNOS is responsible for maintaining low vascular tone and preventing leukocytes and platelets from adhering to the vascular wall [57] Table 1.

\section{Caveolae role in Inflammation!!}

The functional importance of caveolins in inflammatory responses is yet to be elucidated. Yan SR [78] documented the expression of cav 1 in neutrophils but fails to explain its functional role. Hu, et al. [79] described the unique role of caveolin 1 in regulating antimicrobial responses of neutrophils, which under pathological circumstances may contribute to inflammatory tissue injury. The author experimented on cav 1 deficient null mice to study the functional response of neutrophils derived from the bone marrow. He observed that the cav 1 null neutrophils are defective in agonist induced oxidant production, adhesion and transendothelial migration compared with wild type neutrophils. The author also studied the perfused murine lung model in which cav 1 null or wild type neutrophils are perfused through wild type (cav 1 sufficient) and observed that cav 1 null neutrophils are activated with the combination of forml-Met-Leu-Phe (fMLP) and Platelet Activating Factors (PAF) thereby causing less micro vascular injury than the wild type neutrophils.

Caveolae role in inflammation was partly explained by the "Caveolae Signaling Hypothesis". Antibacterial response of neutrophils can be induced by activation of the NADPH oxidase, 


\begin{tabular}{|l|l|l|l|}
\hline \multicolumn{3}{|l|}{ Table 1: Distribution of Cav 1 and Caveolae in NOS Isoenzymes. } \\
\hline $\begin{array}{l}\text { NOS } \\
\text { Isoenzymes }\end{array}$ & eNOS & nNOS & iNOS \\
\hline Originally cloned & Endothelial cells & Neuronal cells & Macrophages \\
\hline $\begin{array}{l}\text { Gene encoding } \\
\text { and its position }\end{array}$ & NOS3 7q35-36 & $\begin{array}{l}\text { NOS1 12q24.2- } \\
31\end{array}$ & $\begin{array}{l}\text { NOS2 17q11.2- } \\
12\end{array}$ \\
\hline $\begin{array}{l}\text { Major regulatory } \\
\text { mechanism }\end{array}$ & $\begin{array}{l}\text { Ca+2 dependent } \\
\text { Ca-calmodulin) } \\
\text { dent (phos- } \\
\text { phorylation, } \\
\text { palmitoylation) }\end{array}$ & $\begin{array}{l}\text { Ca+2 dependent } \\
\text { (Ca-dystrophin) }\end{array}$ & $\begin{array}{l}\text { Ca+2 } \\
\text { independent; } \\
\text { transcriptional } \\
\text { regulation e.g. } \\
\text { by NFB }\end{array}$ \\
\hline $\begin{array}{l}\text { Subcellular } \\
\text { localisation }\end{array}$ & $\begin{array}{l}\text { Golgi apparatus } \\
\text { plasmalemmal } \\
\text { caveolae }\end{array}$ & $\begin{array}{l}\text { Cytosol } \\
\text { endoplasmic } \\
\text { reticulum } \\
\text { sarcollema } \\
\text { postsynaptic } \\
\text { densities } \\
\text { caveolae } \\
\text { (caveolin 3) }\end{array}$ & Phagosomes \\
\hline
\end{tabular}

chemoattractantinduced actin reorganization and migration. Also, over expression of recombinant cav 1 in "engineered phagocytes" (Cos-phox cells) resulted in enhanced chemoattractant - induced superoxide production, thereby providing strong evidence for a signal - enhancing role of caveolin 1 [80, 81].

\section{Caveolae in Cancers!!}

Huang $\mathrm{CF}$, et al. studied the relation between cav 1 and head and neck squamous cell carcinoma and found a reduced expression of caveolin-1 in cancers including head and neck carcinoma [82] but several other studies recognized cav-1 as a tumor promoter because it was over-expressed in various kinds of cancers, especially in oral cancer $[83,84]$. Consistent with the previous reports, their findings showed that highly expressed caveolin-1 was in the cytoplasm, and its expression level was stronger in OSCC (Oral Squamous Cell Carcinoma) than in normal oral mucosa. Hung KE. et al, also showed increasing expression of the marker from normal oral epithelium to dysplastic and neoplastic epithelial tissue (squamous cell carcinoma) [85]. Bau, et al. [86] demonstrated that polymorphism of the cav-1 gene in some genotypex was associated with oral cancer susceptibility.

Keap1-Nrf2 system, as a key signaling pathway that regulates transcription of a series of cytoprotective proteins, plays an important role in oxidative stress, inflammation and carcinogenesis [87]. Keap1 is essential for the regulation of Nrf2 activity; both of them enhanced proliferation, drug resistance and could be potent survival factors in cancers [88]. The strong correlations were observed between caveolin-1 expression and Keap1-Nrf2 system suggesting that caveolin-1 play important role together with Keap1-Nrf2 system in the progression of OSCC.

Gould ML, et al. and Low JY, et al. observed loss of cavin1 expression during the progression of prostate cancer. This down regulation resulted in cell migration, tumor progression and metastasis. All these events occur through the reduce expression of matrix metalloproteases and altered secretion of enzymes, cytokines and growth regulatory proteins. Cavin 1 expression is also decreased in number of cancers like lung cancer and breast cancer, cavin 2 is down regulated in breast, kidney and prostate cancers as well whereas cavin 3 is down regulated in ovarian cancers and breast cancers. Cavin 1 and Cav 1 are cotranscriptionally regulated to modulate oncogenic function and to enhance aggressiveness. ${ }^{20]}$

In colon cancer, the established Wnt signaling pathway became one of the attractive potential caveolin-1 targets. This was substantiated by reports by Hulit, Bash, et al. 2000, on one hand caveolin-1 expression prevented transcription of cyclinD1 by sequestering $\beta$ catenin and on the other hand survivin is a $\beta$ catenin/Tcf/lef target gene [89]. Hence, assuming these roles the authors recognized that caveolin-1 controlled survivin expression by sequestering $\beta$ catenin at the plasma membrane [90]. Subsequently this ability required the expression of E-cadherin in colon cancer and melanoma cell lines [91]. Lobos-González L, et al. suggested that the combined loss of caveolin- 1 and E-cadherin in epithelial cells is likely to promote increased expression of genes relevant to epithelial-mesenchymal transition, loss of cellcell contacts and cell transformation [92] Table 2.

\section{Role of Cav 1 in Odontogenic Cysts and Tumors!!}

Among caveolin proteins, cav-1 is highly expressed in

Table 2: Cav 1 expression in different types of human cancer

\begin{tabular}{|c|c|c|c|c|c|}
\hline \multirow[b]{2}{*}{ Tissue affected } & \multicolumn{5}{|c|}{ Caveolin - 1 expression } \\
\hline & Normal & Cancer - early phase & Cancer - late phase & In vivo study & In Vitro study \\
\hline Breast cancer & High expression & Low expression & Metastasis & $\begin{array}{l}\text { Increased susceptibility } \\
\text { to tumors }\end{array}$ & $\begin{array}{l}\text { High susceptibility } \\
\text { to chemotherapy; } \\
\text { Invadopodia }\end{array}$ \\
\hline Lung & High expression & Low expression & Metastasis & Hyperplasia & $\begin{array}{l}\text { Cell polarization and } \\
\text { migration }\end{array}$ \\
\hline Melanoma & Not known & Not known & Metastasis & Not known & Not known \\
\hline $\begin{array}{l}\text { Oral Squamous Cell } \\
\text { Carcinoma }\end{array}$ & High expression & Low expression & Metastasis & Not known & Not known \\
\hline
\end{tabular}


epithelial cells including keratinocytes, salivary glands and respiratory tract epithelium, as well as, osteoblasts, endothelial cells and skeletal muscles $[93,94]$. Schwab, et al. reported cav1 expression in epithelial and mesenchymal cells of tooth germ in various stages of development, suggesting that cav-1 could participate in odontogenesis [95].

The odontogenic cystic lesions extensively expressed Cav 1 in the basal cell layer showing both membrane and cytoplasmic staining whereas few odontogenic tumors showed immunoreactivity to a smaller degree and more focally. This suggested that cav- 1 could be a tumor suppressor in odontogenic tumors. Jaafari-Ashkavandi Z, et al. [96] demonstrated immunoreaction of cav 1 in the basal cells of cysts and tumors, and reported that this marker is not related to proliferation activity. Various researches have been studied on the expression of proliferation markers (such as Ki-67) in odontogenic cysts and tumors which reported higher proliferative activity in tumors compared to cysts [97]

Expression of cav-1 has been reported in enamel organ, particularly inner enamel epithelium and ameloblast cells of developing tooth germ [95]. It was also demonstrated that cav-1 participated in cell transformation and differentiation [98]. But the immunoreaction of cav 1 appeared clearly in less differentiated cells of cysts and tumors (basal cells, ameloblast-like and some stellate reticulum- like cells) and not in differentiated superficial cells of odontogenic cysts and tumors. So, it is hypothesized that cav-1 may be a useful marker for differential diagnosis of odontogenic lesions [96].

\section{Cav 1 in Salivary Gland Tumors!!}

Cav 1 is strongly expressed in the ductal epithelial cells of normal salivary glands but the physiologic function of caveolae and cav 1 in normal salivary gland is yet to be elucidated. It was suggested that, TRPC 1(Transient Receptor Potential Canonical 1) is a transmembrane protein that is expressed by salivary glands. The TRPC 1 functions in salivary gland secretion and as a store operator for ca2+ influx mechanism. It localizes with cav 1 and its function depends upon the presence of cholesterol and/or on the integrity of the cholesterol rich caveolae [3].

Cohen AW, et al. observed down regulated expression of cav 1 which could be due to transcriptional silencing through hypermethylation of the caveolin 1 gene promoter, which further, may nullify cav 1 expression in human cancers. They observed the down regulation of cav 1 in advanced stage, high grade malignancy or those tumors that had longer duration compared with tumors that had shorter duration. This feature indicates the tumor suppressor activity of cav 1 [99].

Hoffman R in 2004, hypothesized that, in the quiescent vasculature, many factors that regulate angiogenesis normally are held together as part of an inactive modular unit (termed as Angosome); and when, angiogenesis is stimulated, the angosome dissociates, thus enabling angiogenic regulators to become active. It is proposed that angosome is present in the caveolae of capillary endothelial cells. The presence of caveolin 1 can inhibit proangiogenic factors. It may act as a master-switch, coordinating events during angiogenesis. This was further supported by Liu J, et al. [100] that angiogenesis activators such as VEGF, basic fibroblastic growth factor and hepatocyte growth factor, down regulate cav 1 in endothelial cells and the down regulation of cav 1 may be an important step along the pathway toward endothelial cell proliferation.

\section{Cav 1 in Sarcomas!!}

Quest AF, et al. in 2008, proposed that in vivo, cav 1 plays a tissue and stage specific modulatory role in cancer [101]. Wiechen, et al. confirmed cav 1 as a tumor suppressor in sarcomas by immunohistochemistry, where they found high cav 1 expression in fibroblasts, smooth muscle cells, adipocytes and endothelial cells with a fine granular membranous and a diffuse cytoplasmic staining pattern [102]. Various other studies focusing on the expression of cav 1 in specific sarcomas have shown that this protein is expressed in the cytoplasm of cells of the mesenchymal benign tumors, including the adipocyte of all types of lipoma and well-differentiated liposarcoma, the myocyte of angiomyolipoma, leiomyoma, and well differentiated leiomyosarcoma [103]. The immunostaining properties appeared uniform among these lesions, with no implication on the gender and age. Conversely, the malignant mesenchymal tumors which are poorly differentiated and dedifferentiated, including leiomyosarcoma and liposarcoma, showed weak immunoreactivity or failed to stain with cav 1, suggesting that loss of cav 1 might be a necessary step towards a differentiation.

Cav 1 was identified as a metastasis associated gene that is a transcriptional target of EWS/FLI1 (Ewing's sarcoma / friend leukemia integration 1 transcription factor) as well as an important determinant of ESFT (Ewing's sarcoma family of tumors) malignant phenotype and tumorigenicity [104]. SáinzJaspeado M, et al. [105] showed that Cav 1 knockdown led to up regulation of Snail and the concomitant loss of e-cadherin expression. Consistently, loss of Cav1 expression inhibited the anchorage-independent growth of EWS cells and markedly reduced the growth of Ewing's sarcoma cell-derived tumors in nude mice xenografts, indicating that Cav 1 promotes the malignant phenotype in Ewing's sarcoma carcinogenesis. They demonstrated that CAV1 controls migration and invasion in ESFT cells in culture by mechanisms involving the production and activation of metalloproteinases In another study Cav1 expression determines the sensitivity of ESFT cells to clinically relevant chemotherapeutic agents [106].

Cantiani L, et al. demonstrated that cav1 act as an oncosuppressor in human osteosarcoma. The down-regulation of cav 1, is the part of osteoblast transformation and osteosarcoma progression [107]. The 6-year follow-up resulted in a better overall survival for osteosarcoma expressing a level of Cav1. Moreover, the majority of primary osteosarcoma showed significantly lower levels of Cav1 than normal osteoblasts suggesting its role as an oncosuppressor. Mayordomo E, et al. 
carried out both in vitro and in vivo study but could not able to conclude that cav 1 is a marker either for good or for bad prognosis. In his, in vitro study, osteosarcoma cell lines forced to over express cav 1, which showed reduced malignancy with inhibited anchorage-independent growth, migration and invasion whereas in vivo study, cav 1 over expression nullified the metastatic ability of osteosarcoma cells. They also showed that c-Src and c-Met tyrosine kinases, which are activated in osteosarcoma, co-localized with cav 1 and were inhibited upon cav 1 over expression [108].

Cav 1 and Caveolin-3, both are expressed specifically in muscle tissue. Cav1 restrict its expression to satellite cells (represents a pool of quiescent reserve elements) whereas Cav 3 expresses in myoblast cells undergoing differentiation and in mature fibers. ${ }^{[109,110]}$ This suggests that timely coordination of Cav1 and Cav3, contributes to skeletal muscle homeostasis. In skeletal muscle sarcoma, Cav3 is considered a sensitive and specific marker [111] and Cav1 is considered a marker of poor differentiation [112] associating its expression to a better prognostic entity. Hence, depending on the varied role of Cav1 in sarcomas, it may be possible to use different targeting options. For example, the sarcomas in which Cav1 act as a tumor suppressor; either a targeted ectopic re-expression or introduction of a CSD (Caveolin Scaffolding Domain) would be a viable option. Also, cases where Cav1 acts as an oncogene, a direct targeting of Cav1 using antisense or indirectly by chemical inhibition, or lowering cholesterol (that disrupts caveolae) may be of great help [113, 114].

\section{Cav role in miscellaneous!!}

Campbell L \& Gumbleton M [115] hypothesized that in psoriasis caveolin -1 negatively regulates key signal transduction pathways in epidermal keratinocytes. The reduced expression in psoriasis, in response to yet unidentified mechanism, a relaxation of caveolin 1 negative regulatory role results in keratinocyte hyperproliferation and development of Psoriasiform hyperplasia. This made them propose that a reciprocal relationship between cav 1 expression and hyperproliferative non-malignant disorder. Pathobiology of psoriasis supports that aberrant signaling through the EGFR is an important basis to the keratinocytes hyperproliferation. Neovascularization mediated by VEGF is an early and critical event in the development of psoriatic plaque. VEGF secreted near the vicinity of epidermis causes down regulation of cav 1 in keratinocytes thus, relaxing the controlled function of EGFR system. Also, abnormal calcium hemostasis within the keratinocytes imparts some role of cav 1 . The psoriatic keratinocytes fails to sustain high intracellular levels of calcium, required for normal keratinocyte differentiation, causing dysfunctional or loss of cav 1 [115].

Caveolin expression has also been defined in a variety of vascular neoplasms, including capillary hemangiomas, targetoid hemosiderotic hemangiomas, tufted angiomas, angiosarcomas, Kaposi's sarcoma, and epithelioid hemangioendotheliomas [116]. Bayer-Garner I, et al. studied immunohistochemical analysis of the scaffolding protein caveolin but failed to discriminate among benign and well-differentiated smooth muscle and adipocyte neoplasms. He observed Caveolin immunostaining in both the nucleus and cytoplasm of cells of mesenchymal tumors, including the adipocyte of all types of lipoma and welldifferentiated liposarcoma, the myocyte of angiomyolipoma, leiomyoma, and well-differentiated leiomyosarcoma whereas all the poorly differentiated and dedifferentiated sarcoma, including leiomyosarcoma and liposarcoma, showed weak immunoreactivity or failed to stain with caveolin. So, these observations presented some important pathogenic implications [117].

\section{Acknowledgement}

We would like to acknowledge the Management, Dean and Vice Dean of Buraydah Private Dental College for allowing us to carry out our work successfully.

\section{Conclusion}

The dualistic nature and role of caveolae and caveolin 1, intends to investigate the involvement of caveolae assembly and disassembly in the tumor progression. The ever-changing view of their function in mammalian physiology is in part due to the difficulty of working with such membrane domains and a lack of different but complementary tools available for rigorous analyses. It is now mandatory to put caveolae in the multimolecular signaling platforms like lipid rafts and focal adhesions, as this maybe the potential target for novel therapeutics in the current future.

\section{References}

1. Sahai, E. Mechanisms of cancer cell invasion. Curr Opin Genet Dev. 2005;15:87-96

2. Goetz JG, Lajoie P, Wiseman SM, Nabi IR. Caveolin-1 in tumor progression: The good, the bad and the ugly. Cancer Metastasis Rev. 2008;27:715-735.

3. Shi L, Chen XM, Wang L, Zhang L and Chen Z. Expression of Caveolin - 1 in mucoepidermoid carcinoma of the salivary glands: Correlation with Vascular Endothelial Growth Factor, Microvessel Density and Clinical Outcome. Cancer 2007;109(8):1523 - 1531.

4. Palade GE and Bruns RR. Structural modulations of plasma-lemmal vesicles. J Cell Biol. 1968;37(3):633-649.

5. Gabella G. Inpocketing of the cell membrane (Caveolae) in the rat myocardium. J Ultrastruct Res. 1978;65: 135 - 147.

6. Glenney JR Jr, Soppet D. Sequence and expression of caveolin, a protein component of caveolae plasma membrane domains phosphorylated on tyrosine in Rous sarcoma virus -transformed fibroblasts. Proc Natl Acad Sci USA 1992;89:10517-10521.

7. Kurzchalia TV, Dupree P, Parton RG, Kellner R, Virta H, Lehnert M et al. VIP21, a 21-kD membrane protein is an integral component of trans-Golgi-network-derived transport vesicles. J Cell Biol 1992;118(5):1003-1014.

8. Monier S, Dietzen DJ, Hastings WR, Lublin DM, Kurzchalia TV. Oligomerization of VIP21-caveolin in vitro is stabilized by long chain fatty acylation or cholesterol. FEBS Lett. 1996;388(2-3):143-149. 
9. Hansen CG, Nichols BJ. Exploring the caves: Cavins, caveolins and caveolae. Trends Cell Biol. 2010;20(4):177-186.

10. Liu L, Pilch PF. A critical role of cavin (polymerase I and transcript release factor) in caveolae formation and organization. J Biol Chem. 2008:283:4314-4322.

11. Hill MM, Bastiani M, Luetterforst R, Kirkham M, Kirkham A, Nixon SJ et al. PTRF - Cavin,a conserved cytoplasmic protein required for caveola formation and function. Cell. 2008;132(1):113-124

12. Ludwig A, Howard G, Mendoza-Topaz C, Deerinck T, Mackey M, Sandin $\mathrm{S}$, et al. Molecular composition and ultrastructure of the caveolar coat complex. PLoS Biol. 2013;11:e1001640.

13. Gambin Y, Ariotti N, McMahon KA, Bastiani M, Sierecki E, Kovtun O, et al. Single-molecule analysis reveals self-assembly and nanoscale segregation of two distinct cavin sub complexes on caveolae. Elife. 2013;3:e01434

14. Hansen CG, Howard G, Nichols BJ. Pacsin 2 is recruited to caveolae and functions in caveolar biogenesis. J Cell Sci. 2011;124(Pt 16):27772785

15. Stoeber M, Stoeck IK, Hänni C, Bleck CK, Balistreri G, Helenius A Oligomers of the ATPase EHD2 confine caveolae to the plasma membrane through association with actin. EMBO J. 2012;31(10):23502364

16. Oh P, McIntosh DP, Schnitzer JE. Dynamin at the neck of caveolae mediates their budding to form transport vesicles by GTP-driven fission from the plasma membrane of endothelium. J Cell Biol 1998:141:101-114.

17. Engelman JA, XL Zhang, and MP Lisanti. Genes encoding human caveolin-1 and -2 are co-localized to the D7S522 locus (7q3 1.1) a known fragile site (FRA7G) that is frequently deleted in human cancers. FEBS Lett. 1999;436:403-10.

18. Williams TM and MP Lisanti. The caveolin proteins. Genome Biol. 2004;5(3):214

19. Ren X, A.G. Ostermeyer, L.T. Ramcharan, Y. Zeng, D.M. Lublin, and D.A. Brown. 2004. Conformational defects slow Golgi exit, block oligomerization, and reduce raft affinity of caveolin-1 mutant proteins. Mol Biol Cell. 15(10):4556-4567.

20. Lamaze C and Torrino S. Caveolae and Cancer: A New Mechanical Prespective. Biomed J. 2015;38(5):367-379.

21. Fernandez I, Ying Y, S Albanesi J, and Anderson R GW. Mechanism of caveolin filament assembly. Proc. Natl. Acad. Sci. U. S. A. 2002; 99(17): 11193-11198.

22. Schlegel A, Schwab RB, Scherer PE, and Lisanti MP. A role for the caveolin scaffolding domain in mediating the membrane attachment of caveolin-1. The caveolin scaffolding domain is both necessary and sufficient for membrane binding in vitro. J. Biol. Chem. $1999 ; 274: 22660-22667$

23. Galbiati F, Razani B, Lisanti MP. Emerging themes in lipid rafts and caveolae. Cell. 2001;106(4):403-411.

24.Simons K, Toomre D. Lipid rafts and signal transduction. Nat Rev Mol Cell Biol. 2000;1:31-39.

25. Williams TM, Lisanti MP. The caveolin proteins. Genome Biol. 2014;5:214

26. Machleidt T, Li WP, Liu P and Anderson RG. Multiple domains in caveolin-1 control its intracellular traffic. J CellBiol. 2000;148,17-28.
27. DuFort CC, Paszek MJ, Weaver VM. Balancing forces: Architectural control of mechanotransduction. Nat Rev Mol Cell Biol. 2011;12:308319 .

28. Yu H, Mouw JK, Weaver VM. Forcing form and function: Biomechanical regulation of tumor evolution. Trends Cell Biol. 2011;21:47-56.

29. Paszek MJ, Zahir N, Johnson KR, Lakins JN, Rozenberg GI, Gefen A, et al. Tensional homeostasis and the malignant phenotype. Cancer Cell. 2005;8:241-254.

30. Lopez JI, Kang I, You WK, McDonald DM, Weaver VM. In situ force mapping of mammary gland transformation. Integr Biol (Camb). 2011;3:910-921.

31. Sinha B, Köster D, Ruez R, Gonnord P, Bastiani M, Abankwa D et al. Cells respond to mechanical stress by rapid disassembly of caveolae. Cell. 2011;144(3):402-413.

32. Liu P, Rudick M and Richard. Multiple functions of Caveolin - 1. J Biol chem. 2002;277: 41295 - 41298

33.Smart, E. J., Ying, Y., Donzell, W. C., and Anderson, R. G. A role for caveolin in transport of cholesterol from endoplasmic reticulum to plama membrane. J. Biol. Chem. 1996;271(46):29427-29435.

34.Graf GA, Matveev SV, and Smart EJ. Class B scavenger receptors, caveolae and cholesterol homeostasis. Trends Cardiovasc Med. 1999;9(8):221-225.

35. Ito J, Nagayasu Y, Kato K, Sato R, and Yokoyama S. Multiple Functions of Caveolin-1. J Biol Chem. 2002;277: 7929-7935.

36. Le PU, Guay G, Altschuler Y, and Nabi IR. Caveolin-1 is a negative regulator of caveolae-mediated endocytosis to the endoplasmic reticulum. J Biol Chem. 2002;277(5):3371-3379.

37. Engelman JA, Zhang XL, Galbiati F, Lisanti MP. Chromosomal localization, genomic organization, and developmental expression of the murine caveolin gene family (Cav-1, -2 , and -3 ). Cav-1 and Cav2 genes map to a known tumor suppressor locus (6-A2/7q31). FEBS Lett 1998;429:330-336

38. Engelman JA, Zhang XL, Lisanti MP. Genes encoding human caveolin-1 and -2 are co-localized to the D7S522 locus (7q31.1), a known fragile site (FRA7G) that is frequently deleted in human cancers. FEBS Lett. 1998;436(3):403-410.

39. Lee H, Park DS, Razani B, Russell RG, Pestell RG, Lisanti MP. Caveolin-1 mutations (P132L and null) and the pathogenesis of breast cancer: Caveolin-1 (P132L) behaves in a dominant-negative manner and caveolin-1 (-/-) null mice show mammary epithelial cell hyperplasia. Am J Pathol. 2002;161:1357-1369.

40. Rieth MD, Lee J, Glover KJ. Probing the caveolin-1 P132L mutant: Critical insights into its oligomeric behavior and structure. Biochemistry. 2012;51(18):3911-3918.

41. Bonuccelli G, Casimiro MC, Sotgia F, Wang C, Liu M, Katiyar S, et al Caveolin-1 (P132L), a common breast cancer mutation, confers mammary cell invasiveness and defines a novel stem cell/ metastasisassociated gene signature. Am J Pathol. 2009;174(5):1650-662.

42. Li T, Sotgia F, Vuolo MA, Li M, Yang WC, Pestell RG et al. Caveolin-1 mutations in human breast cancer: Functional association with estrogen receptor alpha-positive status. Am J Pathol. 2006;168:19982013.

43. Glenney JR Jr. Tyrosine phosphorylation of a $22-\mathrm{kDa}$ protein is correlated with transformationby Rous sarcoma virus. J Biol Chem. 


\section{$1989 ; 264: 20163-20166$}

44. Kato K, Hida Y, Miyamoto M et al. Overexpression of caveolin- 1 in esophageal squamous cell carcinoma correlates with lymph node metastasis and pathologic stage. Cancer. 2002;94(4):929-933.

45. Yang G, Troung LD, Wheeler TM, Thompson TC. Caveolin- 1 expression in clinically confined human prostate cancer: a novel prognostic marker. Cancer Res. 1999;59(22):5719-5723.

46. Li L, Yang G, Ebara S, Satoh T, Nasu Y, Timme TL et al. Caveolin-1 mediates testosterone-stimulated survival/clonal growth and promotes metastatic activities in prostate cancer cells. Cancer Res. 2001;61(11):4386-4392.

47. Tahir SA, Yang G, Ebara S, Timme TL, Satoh T, Li L et al. Secreted caveolin-1 stimulates cell survival/clonal growth and contributes to metastasis in androgen - insensitive prostate cancer. Cancer Res. 2001;61(10):3882-3885

48. Li L, Ren C, Yang G et al. Caveolin-1 promotes autoregulatory, Aktmediated induction of cancer-promoting growth factors in prostate cancer cells. Mol Cancer Res. 9009;7(11):1781-1791.

49. Tahir SA, Park S, Thompson TC. Caveolin-1 regulates VEGF-stimulated angiogenic activities in prostate cancer and endothelial cells. Cancer Biol Ther. 2009;8(23):2286-2296.

50. Yamaguchi H, Takeo Y, Yoshida S Kouchi Z, Nakamura Y, Fukami K. Lipid rafts and caveolin-1 are required for invadopodia formation and extracellular matrix degradation by human breast cancer cells. Cancer Res. 2009;69(22):8594-8602.

51. Beardsley A, Fang K, Mertz H, Castranova V, Friend S, Liu J. Loss of caveolin-1 polarity impedes endothelial cell polarization and directional movement. J Biol Chem. 2005;280(5):3541-3547.

52. Parat MO, Anand-Apte B, Fox PL. Differential caveolin-1 polarization in endothelial cells during migration in two and three dimensions. Mol Biol Cell. 2003;14(8):3156-3168.

53. Santilman V, Baran J, Anand-Apte B e Robert M. Evans, MarieOdile Parat. Caveolin-1 polarization in transmigrating endothelial cells requires binding to intermediate fi laments. Angiogenesis. 2007;10(4):297-305

54. Pozo MA, Balasubramanian N, Alderson NB, Kiosses WB, GrandeGarcía A, Anderson RG, et al. Phospho-caveolin-1 mediates integrin-regulated membrane domain internalization. Nat Cell Biol. 2005;7(9):901-908.

55.Grande-Garcia A, del Pozo MA. Caveolin-1 in cell polarization and directional migration. Eur J Cell Biol. 2008;87:641-647.

56. Grande-Garcia A, Echarri A, de Rooij J, Nazilla BA,Clare M, WatermanStorer, et al. Caveolin-1 regulates cell polarization and directional migration through Src kinase and Rho GTPases. J Cell Biol 2007;177(4):683-694.

57. Andrew FG, Vicente A.T, Diego AR, Jorge GP and Julio CT. Caveolin-1 in Colon Cancer: The Flexible Connection to Wnt Signaling. Current Cancer Research. 17-41.

58. Salo T, Vered M, Bello IO, Nyberg P, Bitu CC, Zlotogorski Hurvitz A, et al. Insights into the role of components of the tumor microenvironment in oral carcinoma call for new therapeutic approaches. Exp Cell Res. 2014;325(2):58-64.

59. Curry JM, Sprandio J, Cognetti D, Luginbuhl A, Bar-ad V, Pribitkin E, et al. Tumor microenvironment in head and neck squamous cell carcinoma. Semin Oncol. 2014;41(2):217-234.

60. Koontongkaew S. The tumor microenvironment contribution to development, growth, invasion and metastasis of head and neck squamous cell carcinomas. J Cancer. 2013;4(1):66-83.

61. Rivera C, Venegas B. Histological and molecular aspects of oral squamous cell carcinoma (review). Oncol Lett. 2014;8(1):7-11.

62. Goetz JG, Minguet S, Navarro-Lérida I, Lazcano JJ, Samaniego R, Calvo E et al. Biomechanical remodeling of the microenvironment by stromal caveolin-1 favors tumor invasion and metastasis. Cell. 2011;146:148163.

63. Kamochi N, Nakashima M, Aoki S, Uchihashi K, Sugihara H, Toda S, et al. Irradiated fibroblast-induced bystander effects on invasive growth of squamous cell carcinoma under cancerstromal cell interaction. Cancer Sci. 2008;99(12):2417-2427.

64. Li X, Xu Q, Wu Y, Li J, Tang D, Han L, et al. A CCL2/ROS autoregulation loop is critical for cancer-associated fibroblasts-enhanced tumor growth of oral squamous cell carcinoma. Carcinogenesis. 2014;35(6):1362-1370.

65. Hassona Y, Cirillo N, Lim KP, Herman A, Mellone M, Thomas GJ, et al. Progression of genotype-specific oral cancer leads to senescence of cancer-associated fibroblasts and is mediated by oxidative stress and TGF-b. Carcinogenesis. 2013;34(6):1286-1295.

66. Hassona Y, Cirillo N, Heesom K, Parkinson EK, Prime SS. Senescent cancer-associated fibroblasts secrete active MMP-2 that promotes keratinocyte dis-cohesion and invasion. $\mathrm{Br} \mathrm{J}$ Cancer. 2014;111(6):1230-1237.

67. Pal A, Melling G, Hinsley EE, Kabir TD, Colley HE, Murdoch C, et al. Cigarette smoke condensate promotes pro-tumourigenic stromalepithelial interactions by suppressing miR-145. J Oral Pathol Med. 2013;42(4):309-314.

68. Lu HH, Liu CJ, Liu TY, Kao SY, Lin SC, Chang KW. Areca-treated fibroblasts enhance tumorigenesis of oral epithelial cells. J Dent Res. 2008; 87(11):1069-1074.

69. Zhang Z, Dong Z, Lauxen IS, Filho MS, Nor JE. Endothelial cell-secreted EGF induces epithelial to mesenchymal transition and endows head and neck cancer cells with stem-like phenotype. Cancer Res. 2014;74(10):2869-2881

70. Kumar P, Ning Y, Polverini PJ. Endothelial cells expressing Bcl-2 promotes tumor metastasis by enhancing tumor angiogenesis, blood vessel leakiness and tumor invasion. Lab Invest. 2008;88(7):740-749.

71. Warner KA, Miyazawa M, Cordeiro MM, Love WJ, Pinsky MS, Neiva KG, et al. Endothelial cells enhance tumor cell invasion through a crosstalk mediated by CXC chemokine signaling. Neoplasia. 2008;10(2):131139.

72. Ishida T, Hijioka H, Kume K, Miyawaki A, Nakamura N. Notch signaling induces EMTin OSCC cell lines in a hypoxic environment. Oncol Lett. 2013;6(5): 1201-1206.

73.Zhang J, Cheng Q, Zhou Y, Wang Y, Chen X. Slug is a key mediator of hypoxia induced cadherin switch in HNSCC: correlations with poor prognosis. Oral Oncol. 2013;49(11):1043-1050.

74. Lv C, Yang X, Yu B, Ma Q, Liu B, Liu Y. Blocking the Nap/Hpexchanger 1 with cariporide (HOE642) reduces the hypoxia-induced invasion of human tongue squamous cell carcinoma. Int J Oral Maxillofac Surg. 2012;41(10):1206- 1210 . 
75. Thompson TC, Tahir SA, Li L, Watanabe M, Naruishi K, Yang G et al. The role of caveolin-1 in prostate cancer: Clinical implications. Prostate Cancer Prostatic Dis 2010;13:6-11.

76. Madaro L, Antonangeli F, Favia A, Esposito B, Biamonte F, Bouché M et al. Knock down of caveolin-1 affects morphological and functional hallmarks of human endothelial cells. J Cell Biochem 2013;114:18431851.

77. Tkachenko E, Tse D, Sideleva O, Deharvengt SJ, Luciano MR, Xu Y et al. Caveolae, fenestrae and transendothelial channels retain PV1 on the surface of endothelial cells. PLoS One. 2012;7:e32655

78. Yan SR, Fumagalli L, Berton G. Activation of SRC family kinases in human neutrophils. Evidence that p58C-FGR and p53/56LYN redistributed to a Triton $\mathrm{X}-100$-insoluble cytoskeletal fraction, also enriched in the caveolar protein caveolin, display an enhanced kinase activity. FEBS Lett. 1996;380:198-203.

79. Hu G, Ye RD, Dinauer MC, Malik AB, Minshall RD. Neutrophil caveolin-1 expression contributes to mechanism of lung inflammation and injury. Am J Physiol Lung Cell Mol Physiol. 2008;294(2):L178-186.

80. Glogauer M, Marchal CC, Zhu F, Worku A, Clausen BE, Foerster I, Marks P, Downey GP, Dinauer M, Kwiatkowski DJ. Rac1 deletion in mouse neutrophils has selective effects on neutrophil functions. J Immunol 2003;170: 5652-5657, 2003.

81.Zemans R and Downey GP. Role of caveolin-1 in regulation of inflammation: different strokes for different folks. Am J Physiol Lung Cell Mol Physiol. 2008:294; L175-L177.

82.Huang CF, Yu GT, Wang WM, Liu B, Sun ZJ et al. Prognostic and predictive values of SPP1, PAI and caveolin-1 in patients with oral squamous cell carcinoma. Int J Clin Exp Pathol 2014;7(9):6032-6039.

83. Zhang ZB, Cai L, Zheng SG, Xiong Y, Dong JH. Overexpression of caveolin-1 in hepatocellular carcinoma with metastasis and worse prognosis: correlation with vascular endothelial growth factor, microvessel density and unpaired artery. Pathol Oncol Res. 2009;15:495-502.

84. Xue J, Chen H, Diao L, Chen X, Xia D. Expression of caveolin-1 in tongue squamous cell carcinoma by quantum dots. Eur J Histochem 2010; 54 e20.

85.Hung KF, Lin SC, Liu CJ, Chang CS, Chang KW, Kao SY. The biphasic differential expression of the cellular membrane protein, caveolin-1, in oral carcinogenesis. J Oral Pathol Med. 2003;32:461-467.

86. Bau DT, Tsai MH, Tsou YA, Wang CH, Tsai CW, Sun SS, Hua CH, Shyue SK, Tsai RY. The association of Caveolin-1 genotypes with oral cancer susceptibility in Taiwan. Ann Surg Oncol. 2011;18:1431-1438.

87. Wang XJ, Sun Z, Villeneuve NF, Zhang S, Zhao F, Li Y, Chen W, Yi X, Zheng W, Wondrak GT, Wong PK, Zhang DD. Nrf2 enhances resistance of cancer cells to chemotherapeutic drugs, the dark side of Nrf2. Carcinogenesis. 2008;29:1235-1243.

88. Hartikainen JM, Tengstrom M, Kosma VM, Kinnula VL, Mannermaa A, Soini Y. Genetic polymorphisms and protein expression of NRF2 and Sulfiredoxin predict survival outcomes in breast cancer. Cancer Res. 2012; 72: 5537-5546.

89. Kolligs, F. T., G. Bommer, Goke B. Wnt/beta-catenin/tcf signaling: a critical pathway in gastrointestinal tumorigenesis. Digestion. 2002;66(3):131-144

90. Torres VA, JC Tapia, Rodríguez DA, Párraga M, Lisboa P, Montoya M, et al. Caveolin-1 controls cell proliferation and cell death by suppressing expression of the inhibitor of apoptosis protein survivin. J Cell Sci 119(Pt 9): 1812-1823.

91. Torres VA, JC Tapia, Rodríguez DA, Párraga M, Lisboa P, Montoya M, et al. Caveolin-1 controls cell proliferation and cell death by suppressing expression of the inhibitor of apoptosis protein survivin. J Cell Sci 119(Pt 9): 1812-1823.

92.Lobos-González L, Aguilar L, Fernández G, Sanhueza C and Quest AFG. Caveolin-1 in Melanoma Progression. Advances in Malignant Melanoma - Clinical and Research Perspectives, Dr. April Armstrong (Ed.), ISBN: 2011; 978-953-307-575-4

93. Liu P, Li WP, Machleidt T, Anderson RG. Identification of caveolin-1 in lipoprotein particles secreted by exocrine cells Cell Biol. 1999;1:369375

94.Li WP, Liu P, Pilcher BK, Anderson RG. Cell-specific targeting of caveolin-1 to caveolae, secretory vesicles, cytoplasm or mitochondria. J Cell Sci. 2001;114:1397-1408.

95. Schwab W, Harada H, Goetz W, Nowicki M, Witt M, Kasper M, Barth K. Immunocytochemical and biochemical detection of EMMPRIN in the rat tooth germ: Differentiation-dependent co-expression with MMPs and co-localization with caveolin-1 in membrane rafts of dental epithelial cells. Histochem Cell Biol. 2007;128:195-203.

96. Jaafari-Ashkavandi Z, Pardis S, Maryam A, Azadeh AT, Ali DZ. Caveolin-1 Expression in Odontogenic Cysts and Ameloblastomas. Turk Patoloji Derg. 2014;30:94-99.

97. Amaral FR, Mateus GC, Bonisson LA, de Andrade BA, Mesquita RA, Horta MC, Marigo Hde A. Cell proliferation and apoptosis in ameloblastomas and keratocystic odontogenic tumors. Braz Dent J. 2012;23: 91-96

98. Williams TM, Lisanti MP. Caveolin-1 in oncogenic transformation, cancer and metastasis. Am J Phisiol. 2005;288: C494-506.

99. Cohen AW, Hanasko R, Schubert W, Lisanti MP. Role of caveolae and caveolins in health and disease. Physiol Rev 2004;84:1341-1379.

100. Liu J, Razani B, Tang S, Terman BI, Ware JA, Lisanti MP. Angiogenesis activators and inhibitors differentially regulate caveolin - 1 expression and caveolae formation in vascular endothelial cells. Angiogenesis inhibitors block vascular endothelial growth factor - induced down regulation of caveolin-1. J Biol Chem. 1999;274:15781-15785.

101. Quest AF, Gitierrez-Pajares JL, Torres VA. Caveolin-1: an ambiguous partner in cell signalling and cancer. J Cell Mol Med. 2008;12:11301150.

102. Wiechen K, Sers C, Agoulnik A, Arlt K, Dietel M, Schlag PM, Scheider U. Down-regulation of caveolin-1, a candidate tumor suppressor gene, in sarcomas. Am J Pathol. 2001;158:833-839.

103. Bayer-Garner I, Morgan M, Smoller BR. Caveolin expression is common among bening and malignant smooth muscle and adipocyte neoplasms. Mod Pathol. 2002;15:1-5.

104. Tirado OM, Mateo-Lozano S, Villar J, Dettin LE, Llort A, Gallego S, Ban J, Kovar H, Notario V. Caveolin-1 (CAV1) is a target of EWS/FLI-1 and a key determinant of the oncogenic phenotype and tumorigenicity of Ewing's sarcoma cells. Cancer Res. 2006; 66: 9937-9947.

105. Sáinz-Jaspeado M, Martin-Liberal J, Lagares-Tena L, MateoLozano S, Muro X Gl and Tirado OM. Caveolin-1 in sarcomas: friend or foe? Oncotarget 2011; 2: $305-312$. 
106. Tirado OM, MacCarthy CM, Fatima N, Villar J, MateoLozano S, Notario V. Caveolin-1 promotes resistance to chemotherapyinduced apoptosis in Ewing's sarcoma cells by modulating PKCalpha phosphorylation. Int J Cancer. 2010; 126: 426-436.

107. Cantiani L, Manara MC, Zucchini C, De Danctis P, Zuntini M, Valvassor L, Serra M, Olivero M, Di Renzo MF, Colombo MP, Picci P, Scotlandi K. Caveolin-1 reduces osteosarcoma metastases by inhibiting c-Src activity and met signalling. Cancer Res. 2007; 67: 7675-7685.

108. Mayordomo E, Machado I, Giner F, Kresse SH, Myklebost O, Carda C, Navarro S, Llombart-Bosch A. A tissue microarray study of osteosarcoma: histopathologic and immunohistochemical validation of xenotransplanted tumors as preclinical models. Appl Immunohistochem Mol Morphol. 2010; 18: 453-461.

109. Song KS, Scherer PE, Tang Z, Okamoto T, Li S, Chafel M, Chu C, Kohtz DS, Lisanti MP. Expression of caveolin-3 in skeletal, cardiac, and smoothmuscle cells. Caveolin- 3 is a component of the sarcolemma and co-fractionates with dystrophin and dystrophin-associated glycoproteins. J Biol Chem. 1996; 271: 15160-15165.

110. Tang Z, Scherer PE, Okamoto T, Song K, Chu C, Kohtz DS, Nishimoto I, Lodish HF, Lisanti MP. Molecular cloning of caveolin-3, a novel member of the caveolin gene family expressed predominantly in muscle. J Biol Chem. 1996; 271: 2255-2261.
111. Fine SW, Lisanti MP, Argani P, Li M. Caveolin-3 is a sensitive and specific marker for rhabdomyosarcoma. Appl Immunohistochem Mol Morphol. 2005; 13: 231-236.

112. Rossi S, Poliani PL, Cominelli M, Bozzato A, Vescovi R, Monti E, Fanzani A. Caveolin 1 is a marker of poor differentiation in rhabdomyosarcoma. Eur J Cancer. 2011; 47: 761-772.

113. Gratton JP, Lin MI, Yu J, Weiss ED, Jiang ZL, Fairchild TA, Iwakiri Y, Groszmann R, Claffey KP, Cheng YC, Sessa WC. Selective inhibition of tumor microvascular permeability by cavtratin blocks tumor progression in mice. Cancer Cell. 2003; 4: 31-39.

114. Tahir SA, Park S, Thompson TC. Caveolin-1 regulates VEGFstimulated angiogenic activities in prostate and endothelial cells. Cancer Biol Ther. 2009;8:2286-2296.

115. Campbell L and Gumbleton M. Aberrant Caveolin - 1 Expression in Psoriasis: A Signalling Hypothesis. IUBMB Life 2000; 50: 361 - 364.

116. Morgan MB, Stevens GL, Tannenbaum M, Salup R. Expression of the caveolins in dermal vascular tumors. J Cutan Pathol 2001;28:24-28.

117. Bayer-Garner I, Morgan M \& Smoller B R. Caveolin Expression is Common among Benign and Malignant Smooth Muscle and Adipocyte Neoplasms. Mod Pathol 2002;15(1):1-5. 